\title{
Interactive Games Using Hand-Eye Coordination Method for Autistic Children Therapy
}

\author{
Azrulhizam Shapi'i, Noor Atifah Abd Rahman, Mohd Syazwan Baharuddin, Mohd Ridzwan Yaakub \\ Faculty of Information Science \& Technology, Universiti Kebangsaan Malaysia, 43600 Bangi, Malaysia \\ E-mail: azrulhizam@ukm.edu.my, haslinarshad@ukm.edu.my,syazwan@ukm.edu.my,ridzwanyaakub@ukm.edu.my
}

\begin{abstract}
Recent studies have found that imbalanced motor skills (hand-eye coordination) among autism spectrum disorder (ASD) or autistic children cause lower efficiency in daily routines. Autistic children need long-term rehabilitation programs to improve their abilities. However, problems with a lack of motivation to participate in conventional therapy and the high cost of therapy sessions arise over time. Autism children are necessary to do repetitive activities every time through therapy sessions. Repetitive activities cause children having less interest to participate in ongoing therapy sessions. Besides, the therapy process usually requires a long time to be implemented that cause the relatively high cost had to be paid by the patient's family. The use of technology is seen as more effective and less annoying for a child with autism. However, the use of games technology requires the gamer to hold a game controller. Proposals for motion-based toothless games using NUI technology, such as the Kinect Xbox 360, to be used in rehabilitation are exciting for patients, but the design elements do not meet the requirements of autistic people. Hence, this research proposes a Kinect game based on design elements for autistic rehabilitation. The objective of this research is to identify a symptom of eye-hand coordination problem and develop a severe game using Kinect technology as the solution to the problem faced by autism children. This technology provides a low-budget solution costs of therapy and games base on the 3D sensor without the use of control equipment which must behold or touch by hand. Moreover, Kinect does not need a controller or additional body-worn attachment during play time. A game prototype was developed and measured, and evaluation resulted in positive feedback from the user and therapists, thus meeting the objective of this study.
\end{abstract}

Keywords — autism; hand-eye coordination; kinect; rehabilitation game; natural user interface.

\section{INTRODUCTION}

The National Autism Society of Malaysia (NASOM) has estimated that there are 47,000 children with autism in the country. A study using mental health computerized adaptive testing (MHCAT) of children aged between 18 months to 36 months in maternal and child health clinics run by Malaysia's Health Ministry showed that the prevalence of ASD in Malaysia is about 1.6 in 1000 children. Autistic children have various types of cognitive and motor deficiencies, with sensory and motor problems are affecting between $30 \%$ and $100 \%$ of patients. Hand-eye coordination problems are motor disabilities that are common in autistic children, and these constrain the children from carrying out daily routines and taking part in the gameplay. Technology has developed in recent years and has generated improvements in rehabilitation, and psychotherapy based on the innovative use of computers as a means of therapy has been introduced into new rehabilitation programs [1]. Autistic children are attracted to the use of computer games and pay additional attention in this setting, with psychotherapeutic effect.
Moreover, autistic children are more likely to engage in these therapy sessions compared to conventional methods [2] [3] [4]. The Kinect sensor is a virtual reality technology that can identify body movements, posture, and voice in three dimensions and its use is proposed in the development of rehabilitation games. The Kinect system does not require the player to hold or use any controllers but instead uses information from the sensor to identify the position of the hands, feet, and head, as well as interpreting the player's movements in the virtual world. Furthermore, Kinect technology is cheaper than other 3D cameras [5]. The main objectives of this study are to determine: (1) the symptoms often faced by children with hand-eye coordination deficiencies; (2) the requirements and elements of a game that can attract the attention of children with autism; and (3) the effectiveness of the prototype Kinect game designed here.

Researchers in various fields such as psychology, computer science, and sociology are at present interested in serious games [6]. Serious games are those that are constructed with aims other than for entertainment. Recent studies have shown that these have been used in diverse fields such as health, education, and training, learning 
culture also ads for defense and public policy. Serious games are used for several health-related problems including rehabilitation, neurological disabilities, psychomotor coordination, speech problems, and obesity. The rationality of using games in the rehabilitation process is that they introduce elements of fun and uncertainty, and are governed by rules and design choices that make the rehabilitation process more entertaining. Studies comparing the potential of Kinect and Optic Track have shown Kinect to be a rehabilitation tool that allows the patient to undergo therapy both in the hospital and at home. Conventional therapy methods require a therapist to supervise the patient to oversee the rehabilitation process and assess progress; however, this method provides an only a limited objective measurement of achievement. The conventional method lacks an emphasis on involvement, meaning that patient engagement in the rehab is less motivated [7]. The development of motion detectors in rehabilitation games makes them much in use.

However, the connections of the reflective markers on the body result in difficulties in movement and a feeling of not being free. Installation costs are also relatively high, and patients need to attend a treatment center for rehabilitation exercises. As a new, alternative rehabilitation method, Kinect helps patients to undergo treatment at home, and no reflective markers or control devices are required. These alternatives help patients reduce the cost of treatment [8]. Children need more motivation than adults since fun is an essential aspect of therapy for these patients. Kinect games tend to motivate autistic children with hand-eye coordination deficiencies since the detectors allow children who have problems holding a remote control to play [9].

\section{MATERIAL AND METHOD}

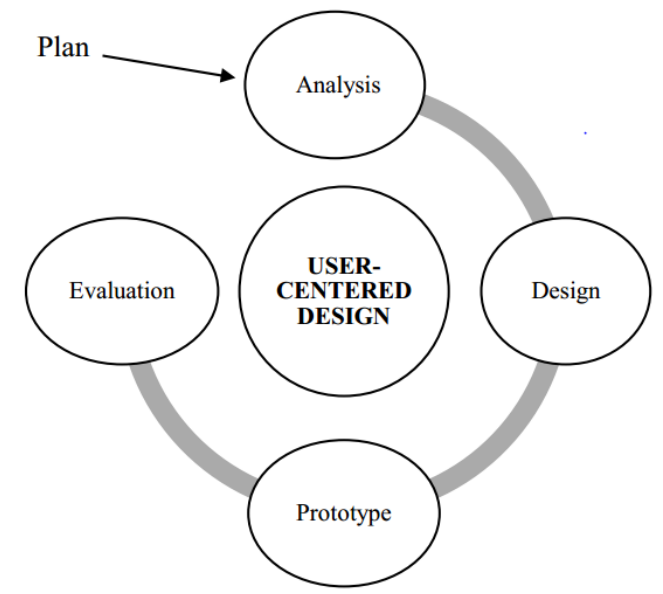

Fig. 1 User-centered design (UCD) model for rehabilitation

The development methodology and design of the prototype game in this study is based on the user-centered design model. Figure 1 shows a flowchart of the modeling phase. UCD has been used in the design of games and video games for the rehabilitation and education of non-traditional populations and is essential in recovery-based games, where it takes into consideration the designer's need to assess the capabilities and limitations of each particular patient in the early stages of designing a recovery system. This approach is based on the ISO standards for human-centered design for interactive games (ISO 9241-210, 2010). The user's involvement varies according to whether the study needs to be fully involved in the analysis process or the involved in a particular phase. This study requires the user to test the prototype developed here. The methodology of the development of this game also emphasizes the needs of users, rather than expecting patients to change or adapt to the game [10].

\section{A. Analysis}

The first phase of the development of this model involves identifying the source of the problem and the objectives. The population, case studies, and observation methods are also determined in this phase. Character type, autism-related problems, and locations for the study are also identified as issues for resolution, enabling an appropriate design to achieve the desired objectives.

\section{B. Design}

The second phase of the study involves a design process based on elements of the game that is appropriate for children with autism, such as the characters, backgrounds, and multimedia elements that need to be included, and the level of the game based on the results of the analysis phase.

\section{Prototype Development}

The third phase of development of the prototype of a hand-eye coordination rehabilitation game is based on information gathered in the analysis and design phases. Prototype development of the Kinect game is carried out according to the requirements of the study.

\section{Evaluation}

The evaluation phase tested the developed prototype with autistic and neurotypical children to determine whether: (1) it is appropriate and functions according to a real environment; (2) it is fun and includes game elements for children with autism; (3) it uses appropriate and attractive graphics; (4) it is interesting; and, most importantly, (5) it achieves the required goals. The book titled game development essentials stated, the main purpose of the user interface is functional rather than aesthetic; as long as an interface function, it can be used [11]. The gaming industry excludes most players with disabilities, and accessibility for disabled children needs to be emphasized in this case. The rules and features that are needed when designing games that can motivate patients to play include the following:

\section{A. Evaluation of Capacity}

The design of the game should be an assessment. The assessment is necessary for the health situation and the ability of patients since performance in the game may vary based on their health. There is a probability that a user could fail to complete the proposed tasks because of a lack of motivation due to health problems.

\section{B. Diversity}

Games and tasks assigned must involve some variation or diversity, in order to reduce boredom and provide motivation 
for tasks such as repeated therapeutic activities for daily rehabilitation activities.

\section{Difficulty Adjustment and Game Continuation}

The most critical therapeutic requirement is to adapt tasks according to the patient's ability, in order to avoid a situation of failure for the patients. Elements of game design for autistic children are different regarding graphics, sound, text and other factors. There are 12 elements in the design of a game that will suit the particular abilities of autistic children [12].

\section{Adaptability}

Each child has different skills; another may not experience a feeling of reward experienced by one individual. Thus, the game should be developed to address the unique capabilities and requirements of each child, implying a high level of adaptability. Elements such as modifying the adaptability of multimedia content, reward, game time and body movement should be included.

\section{E. Variation in Tasks}

The game should change by increasing the complexity of the task for similar activities and continuing to increasing demands regarding motor and cognitive skills and social communication.

\section{F. Unique Goal}

Games must have a unique focus and goal, and the design must include a single task and a clear set of movements that can be followed by children to promote the development of goal-oriented motor control, for example, hand movements in touching an object.

\section{G. Rules}

An understanding of the game is especially important for children with disabilities such as autism. The use of graphic communication symbols and icons to give instructions, for example, to show which body parts must be used and the type of movement required, can be included to help children understand the game.

\section{H. Rewards}

Rewards such as points or additional game time may not be appreciated by children with disabilities such as autism and may elicit a different reaction than for normal children. A positive motivational reward for children with autism can be achieved through entertaining audio and video special effects, such as cheerful music, the sound of applause or funny animated cartoon characters.

\section{Repetition and Prediction}

Repetition is vital to determine the player's level of mastery. It also allows prediction of the next task.

\section{J. Transitions}

The time elapsed before starting a session or switching to a higher level should be short, to prevent children losing their focus.

\section{K. Minimal Use of Graphics}

Children may be distracted by extreme graphical elements, and it is necessary that these should be shown clearly and not overlap with each other. The use of color should also be reduced, as some children are relaxed when dealing with black and white visual elements but become anxious when another color is introduced.

\section{Clear Audio}

The same principles apply to audio as for graphics. Audio must be clear, concise and cheerful, and should serve to complement the task in the game. Audio must also be able to attract the attention of the children, and continue to focus their attention.

\section{Dynamic Stimulus}

Animation and music should be used in the game session to prevent children from losing focus.

\section{N. Fun}

The excitement of the game increases when there is an element of surprise or curiosity, using audio-visual special effects.

\section{O. Avatar}

An avatar is a character that can retain the children's attention as the game progresses.

An analysis of the game elements was conducted through interviews with two therapy teachers. Interviews were conducted to determine the suitability of a game element for autistic children. Respondents were then given questions and asked to provide feedback on the questions, and the Guttmann (1944) scale was used to measure respondents' answers. The results of the analysis are presented in Table I below.

TABLE I

RESULTS OF ANALYSIS OF GAME ELEMENT INTERVIEWS

\begin{tabular}{|c|c|c|}
\hline No & Element & Yes $(\%)$ \\
\hline 1 & Adaptability & $100 \%$ \\
\hline 2 & Different Tasks & $100 \%$ \\
\hline 3 & Unique Goal & $100 \%$ \\
\hline 4 & Rules & $100 \%$ \\
\hline 5 & Rewards & $100 \%$ \\
\hline 6 & Repetition and Prediction & $100 \%$ \\
\hline 7 & Transitions & $100 \%$ \\
\hline 8 & Minimal Graphics & $100 \%$ \\
\hline 9 & Clear Audio & $100 \%$ \\
\hline 10 & Dynamic Stimulus & $100 \%$ \\
\hline 11 & Fun & $50 \%$ \\
\hline 12 & Avatar & $100 \%$ \\
\hline
\end{tabular}


The majority of the elements of the game received positive feedback based on the results of questionnaires and interviews conducted with occupational therapy teachers. However, the element of surprise was not fully agreed upon by respondents, since autistic children process the element of surprise differently from neurotypical children, and may not enjoy surprises.

\section{RESULT AND DISCUSSION}

The development of the Kinect game prototype was based on an analysis and design process that followed a usercentered design model. The development also used game elements that were suitable for autistic children and can motivate according to self-determination theory. A highresolution prototype was developed using the Unity 3D software. Some of the game elements used are shown in the figure below.

\section{A. Rewards}

Rewards are given with each successful drop of a block. Animate of a cartoon character is displayed for every point collected, in order to positively motivate children to continue the game until their ultimate goal is achieved.

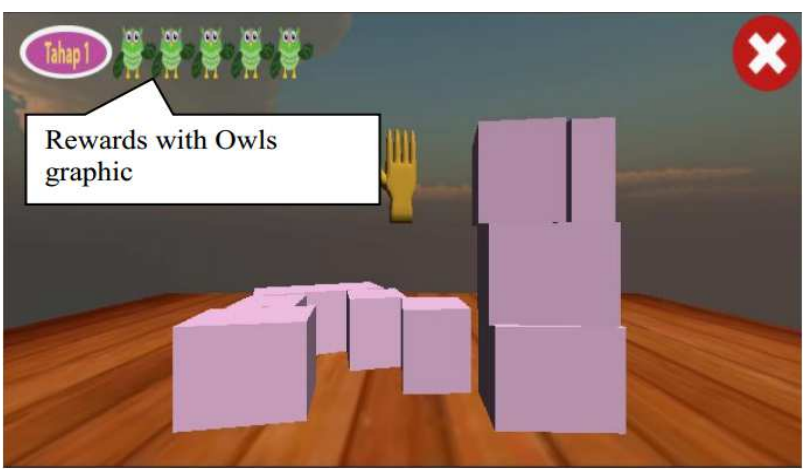

Fig. 2 Rewards in the game

\section{B. Rules}

Rules were used in the development of the game prototype and were displayed using images and text to help autistic children understand.

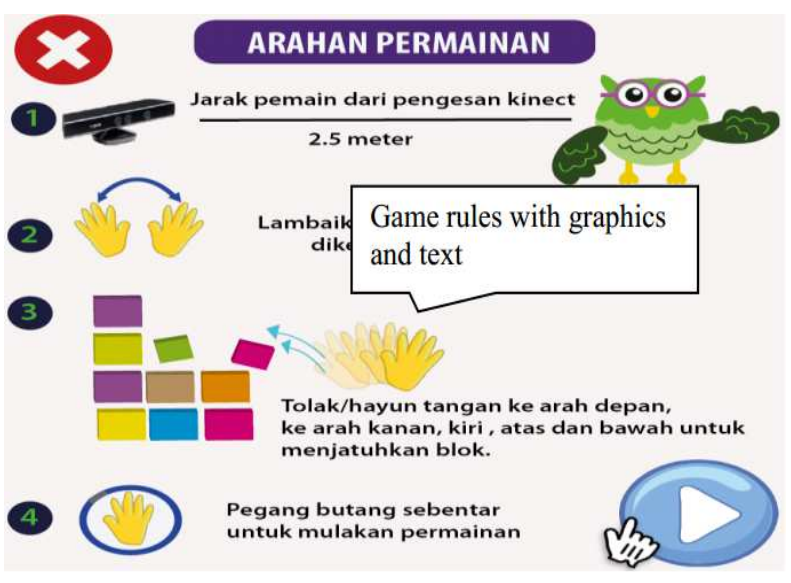

Fig. 3 Game rules

\section{Avatar}

An avatar was designed in the shape of a hand to attract players' attention and make it easier for them to determine their hand position. Children can also focus better on the game through the use of an avatar.

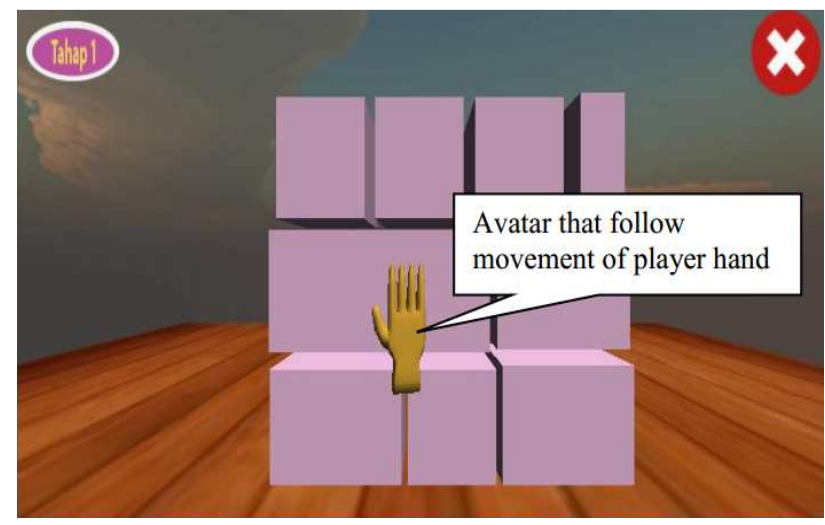

Fig. 4 Avatar used in the game

\section{Different Tasks}

Different tasks were implemented in the game at different levels. There are three levels in the game. The first phase requires the player to drop the blocks by hand swung toward the front. Each level increases in difficulty and children need to coordinate their eyes and hands to move blocks that are in different positions.

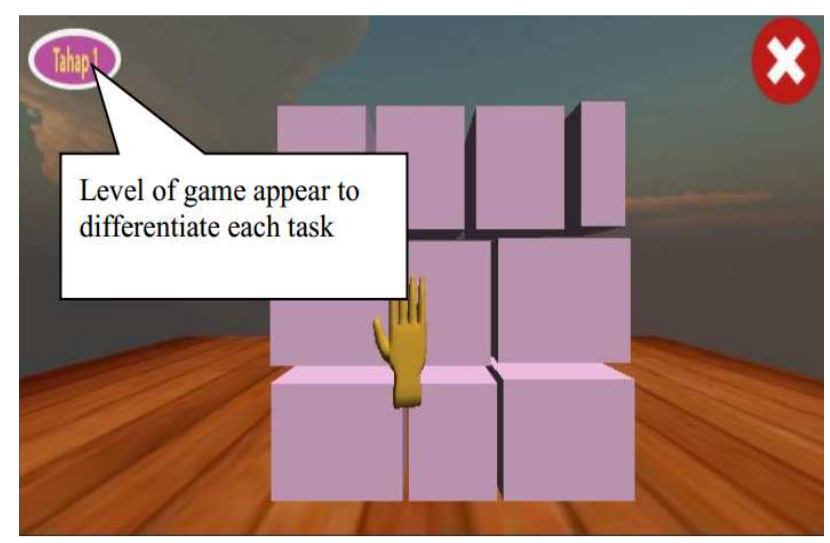

Fig. 5 Different levels of task difficulty

A usability evaluation was conducted to test the prototype for the user. International Standard ISO 9241-11 defines usability testing as determining the extent to which the prototype (product) can be used by specified users to achieve specified goals. The goals are effectiveness (the user completes the task), efficiency (the user completes the task within the time frame given), and satisfaction (the response is based on the user's experience) in the context of a specific use (user, task, equipment, and environment). The testing was done on five children, of which three were autistic and two neurotypical. The prototype testing used a cognitive walkthrough $(\mathrm{CW})$ and interviews on the prototype design. The CW method was used to measure the usability of the game. Four questions were answered during user testing of the prototype: 
- Does the player know what action should be taken?

- Does the player know how to do it?

- Will player recognize an action as the correct one?

\section{E. Will the user understand the feedback?}

The player evaluation results were then analyzed to identify the success or failure of the player in executing an action. If the answer to any of the four questions was 'no,' the result was classified as a failure, while an answer of 'yes' to all four questions was considered a success. The table below shows the results of the design evaluation of the prototype.

TABLE II

RESULTS OF CW EVALUATION

\begin{tabular}{|c|c|c|c|}
\hline Task & Action & Players & $\begin{array}{c}\text { Success } \\
(\%)\end{array}$ \\
\hline 1 & Read rules & $\begin{array}{l}1 \\
2 \\
3 \\
4 \\
5\end{array}$ & $\begin{array}{c}100 \% \\
100 \% \\
50 \% \\
75 \% \\
75 \%\end{array}$ \\
\hline 2 & Press 'Start' button & $\begin{array}{l}1 \\
2 \\
3 \\
4 \\
5\end{array}$ & $\begin{array}{c}100 \% \\
100 \% \\
25 \% \\
50 \% \\
50 \%\end{array}$ \\
\hline 3 & $\begin{array}{l}\text { Wave hand for detection by } \\
\text { sensor }\end{array}$ & $\begin{array}{l}1 \\
2 \\
3 \\
4 \\
5\end{array}$ & $\begin{array}{c}100 \% \\
100 \% \\
50 \% \\
50 \% \\
75 \%\end{array}$ \\
\hline 4 & Swing arm towards the block & $\begin{array}{l}1 \\
2 \\
3 \\
4 \\
5\end{array}$ & $\begin{array}{c}100 \% \\
100 \% \\
50 \% \\
75 \% \\
75 \%\end{array}$ \\
\hline 5 & Press 'Close' button & $\begin{array}{l}1 \\
2 \\
3 \\
4 \\
5\end{array}$ & $\begin{array}{c}100 \% \\
100 \% \\
25 \% \\
50 \% \\
75 \%\end{array}$ \\
\hline
\end{tabular}

The results of the usability evaluation of the prototype shown in the table were analyzed to identify the reasons for the failure of an action. The success of an action is defined as an answer of 'yes' to all four questions and a score of $100 \%$ percent. Failures were analyzed regarding what needed to be corrected, based on the results of observations during play. Neurotypical children did not have problems playing and reading the instructions. Table 3 below shows the types of failure for each action undertaken and the proposed improvements.

In the second stage, interviews regarding the design of the prototype were conducted with the children after CW testing. Five aspects were identified: the ability to support learning (learnability), efficiency, memorability, low error rate and satisfaction with the prototype.
TABLE III

FAILURES AND SUGGESTIONS FOR IMPROVEMENT

\begin{tabular}{|c|c|c|c|}
\hline Task & Action & $\begin{array}{l}\text { Factor causing } \\
\text { failure }\end{array}$ & $\begin{array}{l}\text { Suggestion for } \\
\text { improvement }\end{array}$ \\
\hline 1 & $\begin{array}{l}\text { Read } \\
\text { rules }\end{array}$ & $\begin{array}{l}\text { i. Children with } \\
\text { autism have } \\
\text { problems } \\
\text { understanding and } \\
\text { focusing for long } \\
\text { periods } \\
\text { ii. Poor ability to } \\
\text { memorize }\end{array}$ & $\begin{array}{l}\text { i. Include } \\
\text { instructions } \\
\text { using voice } \\
\text { audio with } \\
\text { the image }\end{array}$ \\
\hline 2 & $\begin{array}{l}\text { Press } \\
\text { the } \\
\text { 'Start' } \\
\text { button }\end{array}$ & $\begin{array}{l}\text { i. Player does not } \\
\text { know what to do } \\
\text { even after reading } \\
\text { the instructions } \\
\text { ii. Failure to hold the } \\
\text { 'Start' button in } \\
\text { the right position. }\end{array}$ & i. Not stated \\
\hline 3 & $\begin{array}{l}\text { Wave } \\
\text { hand for } \\
\text { detectio } \\
\mathrm{n} \text { by the } \\
\text { sensor }\end{array}$ & $\begin{array}{l}\text { i. The player does } \\
\text { not know how to } \\
\text { act } \\
\text { ii. The player does } \\
\text { not understand the } \\
\text { effect of waving } \\
\text { on the detector }\end{array}$ & $\begin{array}{l}\text { i. Include a } \\
\text { hand- } \\
\text { waving } \\
\text { animation } \\
\text { before the } \\
\text { game starts }\end{array}$ \\
\hline 4 & $\begin{array}{l}\text { Swing } \\
\text { arm } \\
\text { towards } \\
\text { the } \\
\text { block }\end{array}$ & $\begin{array}{l}\text { i. The player does } \\
\text { not understand } \\
\text { how to swing hand } \\
\text { towards the front }\end{array}$ & $\begin{array}{l}\text { i. Include } \\
\text { animation } \\
\text { of the } \\
\text { swinging } \\
\text { arm }\end{array}$ \\
\hline 5 & $\begin{array}{l}\text { Press } \\
\text { the } \\
\text { 'close' } \\
\text { button }\end{array}$ & $\begin{array}{l}\text { i. The player does } \\
\text { not understand the } \\
\text { action to be taken }\end{array}$ & $\begin{array}{l}\text { i. Include an } \\
\text { arrow } \\
\text { pointing } \\
\text { towards the } \\
\text { 'Close' } \\
\text { button }\end{array}$ \\
\hline
\end{tabular}

The Guttmann scale (1944) was used to measure the respondents' answers. This scale has only two intervals: agree or disagree. A positive answer was given a score of one, while a negative answer was given a score of zero. The interviews were recorded and the results of the analysis are given in percentages.

TABLE IV

RESULTS OF PROTOTYPE DESIGN EVALUATION

\begin{tabular}{|l|l|c|}
\hline \multicolumn{1}{|c|}{ Aspect } & \multicolumn{1}{|c|}{ Design } & Yes (\%) \\
\hline $\begin{array}{l}\text { The ability to } \\
\text { support } \\
\text { learning } \\
\text { (learnability) }\end{array}$ & $\begin{array}{l}\text { i. } \\
\text { ii. } \begin{array}{l}\text { The design is simple and } \\
\text { easy to understand. } \\
\text { The lack of a controller helps } \\
\text { the player to focus } \\
\text { The hand-shaped avatar } \\
\text { provides functionality to } \\
\text { support the game }\end{array}\end{array}$ & $100 \%$ \\
\hline Memorability & $\begin{array}{l}\text { i. } \\
\text { ii. } \begin{array}{l}\text { Game rules help players } \\
\text { Rules on a single way of } \\
\text { playing in the game help the } \\
\text { player understand the } \\
\text { technique more quickly }\end{array}\end{array}$ & $\begin{array}{c}100 \% \\
100 \%\end{array}$ \\
\hline
\end{tabular}




\begin{tabular}{|c|c|c|}
\hline Low error rate & $\begin{array}{l}\text { i. Automatic level transitions } \\
\text { help the player } \\
\text { ii. Menu structure and the } \\
\text { interface does not confuse } \\
\text { the players }\end{array}$ & $\begin{array}{l}100 \% \\
100 \%\end{array}$ \\
\hline Satisfaction & $\begin{array}{l}\text { ii. The design of the game is } \\
\text { attractive to players? } \\
\text { iii. Minimalistic use of graphics } \\
\text { and colors that are not boring } \\
\text { iv. The player does not feel } \\
\text { stressed while testing the } \\
\text { prototype }\end{array}$ & $\begin{array}{l}100 \% \\
100 \% \\
100 \%\end{array}$ \\
\hline
\end{tabular}

The results of the analysis of the interviews regarding the game design showed that all users agreed with the design used. Improvements recommended by one therapy teacher concerned the rules; it was suggested that the game should use animated arrows to show what should be done, and instructions should be given separately before the start of an action.

\section{CONCLUSION}

The results of this phase of development of the prototype will guide the next design iteration regarding the cognitive and motor skills of autistic children. The failures identified through $\mathrm{CW}$ testing established the need for improvements to the prototype to provide the functions and features required by autistic children.

Moreover, the prototype design evaluation suggested new potential applications for autistic patients that have not been addressed by the current application of therapy games. Suggestions for future research include testing the prototype with a more significant sample population so that the evaluation can be more thorough and the effectiveness of the prototype can be determined. Additional game levels may also reduce the possibility of boredom in the long term.

\section{ACKNOWLEDGMENT}

This research is funded by Regional Cluster for Research and Publication Grant RCRP-2016-002.

\section{REFERENCES}

[1] Baranowski, T., Buday, R., Thompson, D.I., \& Baranowski, J.(2009). Playing for Real: Video Games and Stories for Health-Related Behavior Change. American Journal of Preventive Medicine 34(1), $1-23$.
[2] Wilkinson, N., Ang, R.P., \& Goh. D.H. (2008). Online Video Game Therapy for Mental Health Concerns: A Review. International Journal of Social Psychiatry, 54(4), 370-382.

[3] Shapi i, A., Nor Bahari, N., Arshad, H., Mat Zin,N.A., Mahayuddin, Z.R. (2015). Rehabilitation Exercise Game Model for Post-stroke using Microsoft Kinect Camera, International Conference on Biomedical Engineering (ICoBE), Penang, 117-122.

[4] Elaklouk, A. Mat Zin, N.A., Shapii, A.(2013) Game design for acquired brain injury cognitive rehabilitation: a conceptual framework, Advances in Visual Informatics (Lecture Notes in Computer Science), 218-230

[5] Ceranoglu, T.A.(2010). Video Games in Psychotherapy. Review of General Psychology14(2), 141-146.

[6] Bertachinni, F., Rende, A.D., Bilotta, E., Gabriele. L., Elizabeth, D., \& Valenti, A.(2013). An Emotional Learning Environment for Subjects with Autism Spectrum Disorder. International Conference on Interactive Collaborative Learning (ICL), 653-659.

[7] Smisek, J., Jancosek, M., \& Pajdla, T. (2011). 3D with Kinect. IEEE International Conference on Computer Vision Workshops, 11541160.

[8] Bruer, J., \& Bente, G. (2010). Why so serious? On the relation of serious games and learning. Journal for Computer Game Culture, 4(1), 7-24.

[9] Shapi i, A. Mat Zin, N.A., Elaklouk, A. (2015). A game system for cognitive rehabilitation. Biomed Research International, 1-7.

[10] Chien, Y.C., Lange, B., Mi, Z., Koenig, S., Requejo, P., Somboon, N., Sawchuk, A.A., \& Rizzo, A.A.(2012). Towards Pervasive Physical Rehabilitation Using Microsoft Kinect. 6th International Conference on Pervasive Computing Technologies for Healthcare (Pervasive Health) and Workshops, 159-162.

[11] Ahmed Mohammed Elaklouk, Nor Azan Mat Zin, Azrulhizam Shapii. (2015) Investigating therapists` intention to use serious games for acquired brain injury cognitive rehabilitation, Journal of King Saud University Computer and Information Sciences . 160-169.

[12] Chung, L.L., Ya, L.H., Tzu, K.L., Chien, M.T., Yung, F.C., \& Erdenetsogt, D.(2015). A Microsoft Kinect-based virtual rehabilitation system to train balance ability for stroke patients. International Conference on Cyberworlds, 54-60.

[13] Elaklouk, A, Mat Zin, N. Shapii., (2013). A Conceptual Framework for Designing Brain Injury Cognitive Rehabilitation Gaming System, International, Journal of Digital Content Technology and its Applications, 7(15):31-41

[14] Ave, A.C., Caro, J.D., Pacapac, D.M.C. \& Salamanca, K.M.G.(2013). A Kinesthetic Game as a Motivational Aid and Monitor in Upper Extremities Burns Rehabilitation.Information. Intelligence, Systems, and Applications (IISA), Fourth InternationalConference, 1-3.

[15] Lange, B., Flynn, S., Proffitt, R., Chien, Y.C., Meng, \& Rizzo, A.S (2010). Development of an Interactive Game-Based Rehabilitation Tool for Dynamic Balance Training. Journal of Topic Stroke Rehabilitation 17(5), 345-352.

[16] Novak, J. Game Development Essentials. 3rd ed. USA: DELMAR Cengage Learning.

[17] Bartoli, L., Garzotto, F., Gelsomini, M., Oliveto, L., \& Valoriani, M.(2014). Designing and Evaluating Touchless Playful Interaction for ASD Children. IDC '14: Proceedings of the 2014 Conference on Interaction Design and Children, 17-26. 